\title{
A Syntactic Analysis of Two Types of Predicate Reduplication in Japanese
}

\author{
Yuki Ishihara*
}

LSA Annual Meeting, Minneapolis, January 2-5, 2014

1. Introduction. There are two types of predicate reduplication in Japanese, one for polarity emphasis (1), and the other for emphasizing action (2a) or state (2b). ${ }^{1}$
A: Kinoo gakko-ni it-ta?
yesterday school-to go-PST
'Did you go to school yesterday?'
B: Un, it-ta it-ta.
yes go-PST go-PST
'Yes, I did indeed.'
$\begin{array}{lll}\text { (2) a. Ah, ohiru(-o) } & \text { tabe-ta tabe-ta. } \\ \text { ah } & \text { lunch(-ACC) } & \text { eat-PST eat-PST }\end{array}$
'Ah, I ate lunch to the full.'
b. Ah, kowa-i kowa-i.
ah scary-NPST ${ }^{2}$ scary-NPST
'Ah, it's so scary.'

2. Common properties. Though they differ in the target of emphasis, there are six properties that are common to both types.

2.1. PRODUCTIVITY. They are both productive, and the categorical status does not change by reduplication, unlike cases of lexical reduplication such as osoruosoru 'timidly,' where reduplication of V, osoru 'fear,' results in Adv.

2.2. REgiSTER. They both occur in colloquial speech, and are often accompanied by case-marker drop. (cf. (2a))

2.3. PARALLELISM WITH SENTENCE-FINAL PARTICLES. Both types of predicate reduplication are semantically equivalent to sentences ending with such sentence-final particles (SFPs) as yo and naa, which denote emphasis.
a. Un, it-ta yo. yes go-PST SFP

(semantically equivalent to (1B))

\footnotetext{
* This research is supported by JSPS Grant-in-Aid for Scientific Research (C) 25370544. I am thankful to the audiences at the LSA meeting as well as to Noriko Imanishi, Tomomi Arii, Mioko Miyama, Hiromune Oda, Toshiyuki Yamada and Tohru Noguchi for valuable comments and/or judgments. Author: Yuki Ishihara, Tokyo Institute of Technology (ishihara@flc.titech.ac.jp).

1 Verbs, Adjectives, and Adjectival Nouns can be reduplicated in this construction.

2 NPST in glosses stands for Nonpast tense.
} 
b. Ah, ohiru(-o) tabe-ta naa. (semantically equivalent to (2a)) ah lunch(-ACC) eat-PST SFP

2.4. MAin CLAUSE PHENOMENON. Both types are restricted to root clauses, and are disallowed in embedded complement clauses (4) or relative clauses (5).

a. *Taro-wa [zibun-ga ringo-o tabe-ta tabe-ta to] it-ta.

Taro-TOP self-NOM apple-ACC eat-PST eat-PSTCOMP say-PST

'Taro said that he did eat an apple/ate many apples.'

b. *Taro-wa [ Hanako-ga ringo-o tabe-ta tabe-ta (no) ka] kii-ta.

Taro-TOP Hanako-NOM apple-ACC eat-PST eat-PST COMP COMP ask-PST

'Taro asked if Hanako did eat an apple/ate many apples.'

a. *[Taro-ga yon-da yon-da hon $^{3}$

Taro-NOM read-PST read-PST book

'the book which Taro did read/the book which Taro read many times.'

2.5. TARGET OF REDUPLICATION. The form that is allowed in the reduplication construction is restricted in the same way in both types. While inflected Vs as a whole undergo reduplication, its subpart cannot (6).

a. Tabe-ta tabe-ta/ * tabe-tabe-ta/* tabe-ta-ta.

eat-PST eat-PST/ eat-eat-PST/ eat-PST-PST

'I did eat it./I ate a lot.'

b. Hitto(-o) ut-are-ta ut-are-ta/ *ut-are-ut-are-ta/

hit(-ACC) hit-PASS-PST hit-PASS-PST/hit-PASS-hit-PASS-PST/

*ut-are-are-ta.

hit-PASS-PASS-PST

'He did surrender hits./He surrendered many hits.'

c. Sira-n sira-n/ sira-na-i sira-na-i/

know-NEG know-NEG/ know-NEG-NPST know-NEG-NPST/

*sira-na-i-na-i

know-NEG-NPST-NEG-NPST

'I really don't know.'

Complementizers (7) and modals that occur in COMP (8) cannot be reduplicated along with the inflected $\mathrm{V}$.

a. *Taro-wa hon-o yon-da-to yon-da-to it-ta.

Taro-TOP book-ACC read-PST-COMP read-PST-COMP say-PST

'Taro said that he did read the book/many times.'

${ }^{3}$ When adjectives or adjectival nouns are reduplicated instead of verbs, they can occur in a relative clause, as in hana-ga naga-i naga-i zoo (an elephant with a very long trunk). 

b. *Taro-ni hannin-o mi-ta-(no)-ka mi-ta-(no)-ka

Taro-DAT criminal-ACC see-PST-COMP-COMP see-PST-COMP-COMP

tazune-ta.

ask-PST

'I asked Taro if he had seen the criminal indeed/many times.'

c.?*Ringo(-o) tabe-ta-no tabe-ta-no?

apple(-ACC) eat-PST-Q eat-PST-Q

'Did you really eat the apples/many times?'
?*Ame-ga hur-u-yooda hur-u-yooda/ ?*hur-u-daroo hur-u-daroo.
rain-NOM fall-NPST-seem fall-NPST-seem/ fall-NPST-may fall-NPST-may

'It seems to rain indeed./It seems to rain much./It may rain indeed./It may rain much.'

2.6. PROSODIC CONSTRAINT. In both types, many speakers find it less natural when the target of reduplication consists of many morae.

(9) ??Booto hikkurikaet-ta hikkurikaet-ta.

boat overturn-PST overturn-PST

'The boat was overturned indeed/many times.'

\section{Anaysis.}

3.1. Assumptions. In order to account for these properties, we assume that movement of an element leaves its copies behind and that these copies can be phonologically realized under certain conditions. (Chomsky (1995), Nunes (2004), Bošković \& Nunes (2007)) We also follow Speas \& Tenny (2003), Miyagawa (2012) and Saito (2013) in postulating a Speech Act Phrase (SAP) in the left/right periphery of clauses. Whether or not V moves to higher functional heads syntactically in Japanese has been under debate, but we assume that it does, following Otani and Whitman (1991), Koizumi (1995) and Funakoshi (2012) among others.

3.2. Proposal. We argue that both types of reduplication are derived syntactically in the same way: by moving a tensed $\mathrm{V}$ to SA and by pronouncing both the tensed V in SA and its copy in $\mathrm{T}^{4}$ Specifically, first, we assume that SA selects TP in matrix clauses and that a phonetically-null assertion marker, $\varnothing$, resides in SA of assertive sentences. (cf. Mihara (2011)) Since Japanese is a head-final language, an ordinary assertive sentence ends with $\varnothing$.

Vermeulen (2012) observes that a natural answer to yes/no questions in Japanese consists of an inflected verb with an emphatic stress, and when the SFP yo occurs with it (3a), the stress can be either on the verb or on the SFP. We claim that these are instantiations of a polarity focus feature, which occurs optionally in $\varnothing$, and that another way of phonologically expressing polarity focus is reduplication of tensed predicates. To be more precise, we propose a condition that requires a polarity focus feature, which yields polarity focus interpretation as in (1), be overtly realized. In (10), $\mathrm{V}$, tabe, raises to $\mathrm{T}$ via $\mathrm{v}$ in a regular manner. In addition, the

\footnotetext{
${ }^{4}$ See Martins (2013) for a similar analysis for reduplication in Portuguese.
} 
polarity focus feature in $\varnothing$ triggers its movement further up to SA. Instead of pronouncing tabe-v-ta in SA with a stress, the copy in T, tabe- $v$-ta, can be pronounced along with tabe-v-ta in $\mathrm{SA}$ as a phonological manifestation of the polarity focus feature.

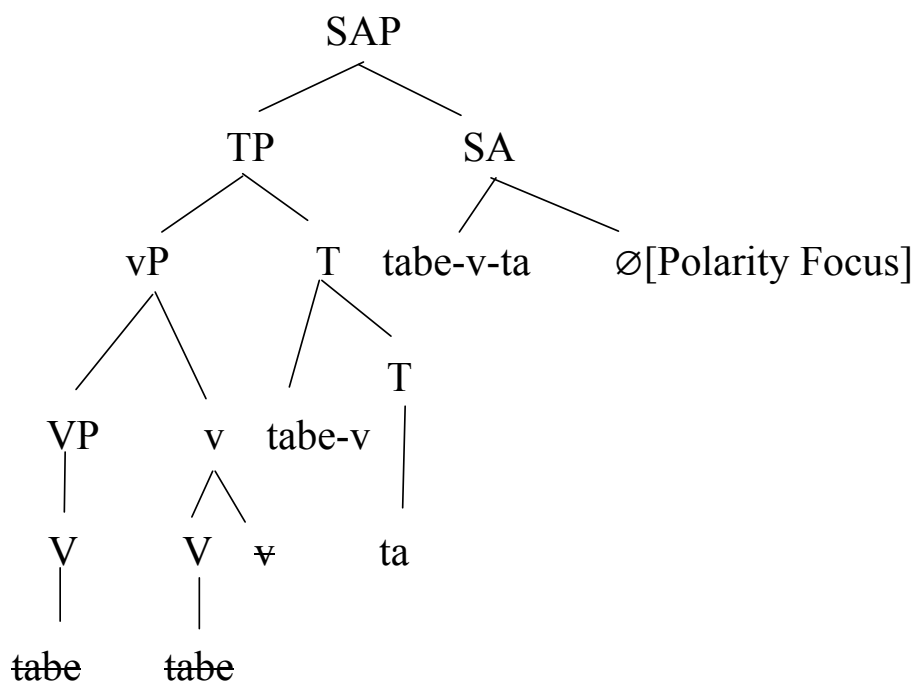

As for predicate emphasis reduplication as in (2), an emphasis feature is present in the assertion marker $\varnothing$, which yields emphatic interpretation depending on the choice of predicates and contexts. Like the polarity focus feature, this emphasis feature triggers movement of the tensed predicate to SA and it must be realized overtly. Again the inflected copy in $\mathrm{T}$ is pronounced along with the moved predicate in SA as a phonological manifestation of the emphasis feature.

4. Conclusion. We have shown that unlike in Nupe (Kandybowicz (2013)), the two types of predicate reduplication in Japanese differ in interpretation but share many syntactic/ phonological/pragmatic properties, and proposed to derive them in the same manner, attributing their interpretive differences to the two different features on the phonetically-null assertion marker. To the extent that our analysis is successful, it provides another piece of evidence for Verb Raising in Japanese.

\section{Selected References}

Bošković, Željko and Jairo Nunes. 2007. The Copy Theory of Movement: A View from PF. In Norbert Corver \& Jairo Nunes (eds.), The Copy Theory of Movement. 13-74. Amsterdam: John Benjamins.

Ishihara, Yuki. 2013. Verbal Reduplication for Polarity Emphasis in Japanese. Linguistic Research: Working Papers in English Linguistics 29. 31-58.

Kandybowicz, Jason. 2013. Ways of Emphatic Scope-Taking: From Emphatic Assertion in Nupe to the Grammar of Emphasis. Lingua 128. 51-71.

Martins, Ana Maria. 2013. Emphatic Polarity in European Portuguese and Beyond. Lingua 128. 95-123.

Speas, Peggy \& Carol Tenny. 2003. Configurational Properties of Point of View Roles. In Anna Maria Di Sciullo (ed.), Asymmetry in Grammar. 315-343. Amsterdam: John Benjamins.

Vermeulen, Reiko. 2012. The Information Structure of Japanese. In Manfred Krifka \& Renate Musan (eds.), The Expression of Information Structure. 187-216. Berlin: Mouton de Gruyter. 